Observational study

\section{Trends in maternal morbidity relating to time of delivery need further exploration}

$10.1136 /$ eb-2016-102313

Marian Knight

National Perinatal Epidemiology Unit, University of Oxford, Oxford, UK

Correspondence to: Professor Marian Knight, National Perinatal Epidemiology Unit, University of Oxford, Old Rd Campus, Oxford OX3 7LF, UK; marian.knight@npeu.ox.ac.uk

Commentary on: Lyndon A, Lee HC, Gay C, et al Effect of time of birth on maternal morbidity during childbirth hospitalization in California. Am J Obstet Gynecol 2015;213:705.e1-11.

\section{Implications for practice and research}

- Women giving birth at night may be a higher risk population, reinforcing the need for regular observations to detect morbidities early.

- Further research is needed taking into account the time of severe morbidity events and their underlying causes in order to investigate variation in outcomes by the time of day.

\section{Context}

There is increasing interest worldwide, particularly in high-resource countries, in assessing variation in the outcomes of maternity care according to the time of day or day of the week. Such analyses are usually intended to examine the impact of variation in staffing levels or capacity, with the aim of identifying actions to improve the safety of maternity care. This study by Lyndon et al focused on the outcomes of pelvic floor morbidity and severe maternal morbidity, and it examined the occurrence of these in relation to the time and day of women's delivery.

\section{Methods}

This study used linked hospital data from California on almost 1500000 women who gave birth between 2005 and 2007 to investigate the incidence of pelvic floor morbidity (including episiotomy as well as third and fourth degree tears) and severe maternal morbidity (a composite outcome including 12 different morbidities such as postpartum haemorrhage). The variation in incidence of these morbidities was investigated according to the time of day the women gave birth, adjusted for possible confounding or risk factors, including maternal age, race, ethnicity, level of education, insurance status, adequacy of prenatal care and presence of preeclampsia or chronic hypertension.

\section{Findings}

Almost 16\% of women had a pelvic floor morbidity, and $0.6 \%$ had a severe maternal morbidity. After adjustment, pelvic floor morbidity was more likely in women who gave birth between 11:00 and 23:00, and severe maternal morbidity was more likely in women who delivered between 23:01 and 07:00. Caesarean delivery, older maternal age, preeclampsia, chronic hypertension, lack of or government insurance, Hispanic ethnicity and Caucasian race were also associated with severe maternal morbidity.

\section{Commentary}

The study used routine hospital data to examine variation in outcomes according to the time of birth. Studies using routine hospital data have a number of limitations. ${ }^{1}$ Adjustment for potential confounding factors can only be made when the relevant information is available within the data set used. The authors of this study were unable to adjust for maternal obesity or smoking, both known to be associated with morbidity. ${ }^{2}{ }^{3}$ Similarly, they made no adjustments for maternal morbidities beyond chronic hypertension and pre-eclampsia. Many pre-existing medical conditions are known to be associated with severe maternal morbidity. ${ }^{4}$ There is thus a significant likelihood that the women giving birth at night are different to those giving birth during the day in ways unaccounted for by this study.

Another challenge in using routine data concerns the time variable used. Time of birth was used in this study. However, the events underlying the eventual outcomes are likely to occur at a time remote from the actual time of delivery. The staffing in place overnight at the time of delivery has little relevance when the underlying cause of the severe morbidity was a disease process and/or management which began hours or even days beforehand. Future studies need to investigate the timing and underlying causes of morbidity to gain further insight as to whether there is true 'night-time effect'.

What this study does tell us is that the women giving birth overnight are more likely to have a severe morbidity than those giving birth during the day and that women giving birth during the day are more likely to have a pelvic floor morbidity. In the light of other studies that have shown that basic observations are not always undertaken, ${ }^{5}$ and with the knowledge, from this study, of which morbidities are more likely to occur during the day and at night, this study highlights the importance of regular observations to detect and manage morbidities early.

Competing interests None declared.

Provenance and peer review Commissioned; internally peer reviewed.

\section{References}

1. Li L, Rothwell PM, Oxford Vascular Study. Biases in detection of apparent "weekend effect" on outcome with administrative coding data: population based study of stroke. BMJ 2016;353:i2648.

2. Heslehurst N, Simpson H, Ells LJ, et al. The impact of maternal BMI status on pregnancy outcomes with immediate short-term obstetric resource implications: a meta-analysis. Obes Rev 2008;9:635-83.

3. Phelan S. Smoking cessation in pregnancy. Obstet Gynecol Clin North Am 2014;41:255-66.

4. Nair M, Kurinczuk JJ, Knight M. Ethnic variations in severe maternal morbidity in the UK-a case control study. PLoS One 2014;9:e95086.

5. Knight M, Kenyon S, Brocklehurst P, et al. Saving lives, improving mothers' carelessons learned to inform future maternity care from the UK and Ireland confidential enquiries into maternal deaths and morbidity 2009-12. 0xford: National Perinatal Epidemiology Unit, University of Oxford, 2014. 


\section{EBN Trends in maternal morbidity relating to time of delivery need further exploration}

Marian Knight

Evid Based Nurs published online August 12, 2016

Updated information and services can be found at:

http://ebn.bmj.com/content/early/2016/08/12/eb-2016-102313

These include:

References This article cites 4 articles, 1 of which you can access for free at: http://ebn.bmj.com/content/early/2016/08/12/eb-2016-102313\#BIBL

Email alerting Receive free email alerts when new articles cite this article. Sign up in the service box at the top right corner of the online article.

Topic
Collections

Articles on similar topics can be found in the following collections

Midwifery (53)

Notes

To request permissions go to:

http://group.bmj.com/group/rights-licensing/permissions

To order reprints go to:

http://journals.bmj.com/cgi/reprintform

To subscribe to BMJ go to:

http://group.bmj.com/subscribe/ 